\title{
DESAIN SAMPUL DEPAN BUKU CERITA BERGAMBAR JOKO TOLE
}

\author{
Bairy Tri Saputra Pamungkas ${ }^{1)}$, Nadila Ruhbani Edward ${ }^{2)}$, Herliyana Rosalinda ${ }^{3)}$ \\ Program Studi Desain Komunikasi Visual, \\ Fakultas Bahasa dan Seni, Universitas Indraprasta PGRI \\ Jl. Nangka 58 C Tanjung Barat, Jakarta Selatan, 12530, Indonesia \\ Bairy.pamungkas@gmail.com
}

\begin{abstract}
Abstrak
Joko tole adalah salah satu cerita rakyat dari Madura. Cerita ini mengisahkan tentang seorang pemuda bernama Joko Tole yang merupakan panglima perang kerajaan yang menikahi putri raja yang buta. Penelitian ini bertujuan untuk merancang sampul buku cerita bergambar Joko Tole sebagai media informasi dan hiburan untuk anak-anak. Metode yang dilakukan adalah penelitian kualitatif deskriptif. Pada umumnya, para pembaca pertama kali akan melihat sampul dari buku. Sampul buku yang menarik dapat membuat para pembaca tertarik untuk melihat isi dari buku tersebut. Oleh karena itu, perancangan sampul buku cerita bergambar Joko Tole ini berupaya menampilkan desain sampul yang sesuai dengan budaya yang ada di cerita Joko Tole. Pada desain tokohnya dimasukan ciri khas pakaian orang Madura sebagai identitas budaya Madura.
\end{abstract}

Kata Kunci: Joko Tole, Sampul, Cerita Rakyat.

\begin{abstract}
Joko tole is one of the folk tales from Madura. This story tells of a young man named Joko Tole who is a royal warlord who marries blind princess. This study aims to design the cover of Joko Tole's pictorial storybook as a medium of information and entertainment for children. The method used is descriptive qualitative research. In general, readers will first see the cover of the book. An attractive book cover can make readers interested in seeing the contents of the book. Therefore, the design of the book cover with the picture of Joko Tole seeks to present a cover design that is in accordance with the culture in Joko Tole's story. In the design of the characters, the characteristics of Madurese clothing are included as Madurese cultural identity.
\end{abstract}

Keywords: Joko Tole, Cover, Folklore

Correspondence author: Bairy Tri Saputra Pamungkas, Bairy.pamungkas@gmail.com, Jakarta, and ndonesia

This work is licensed under a $C C-B Y-N C$

\section{PENDAHULUAN}

Cerita rakyat menjadi salah satu warisan budaya lisan di Nusantara. Banyak cerita rakyat yang ditujukan untuk memberi edukasi bagi anak-anak. Pemaknaan nilai dan alur cerita banyak terdapat kemiripan, misalnya dari cerita Sampuraga dari Sumatera Utara, mirip dengan cerita Malin Kundang dari Sumatera Barat. Hal-hal yang menjadi pembeda dari cerita-cerita tersebut, 
yaitu dari latar tempat, budaya, penamaan tokoh dan daerah serta bahasa yang digunakan. Tokohtokoh yang dimunculkan, banyak merupakan tokoh yang dapat dijadikan teladan, misalnya di Jawa Tengah terdapat kisah Joko Tarub, Joko Kendil dan Joko Tinggkir, dan Jawa Timur terdapat kisah Joko Tole. Cerita rakyat Joko Tole berasal dari Madura. Cerita ini merupakan rangkaian kisah perjalanan hidup Joko Tole dari usia anak-anak hingga ia menjadi Adipati Sumenep. Pada artikel ini, perancangan sampul depan buku cerita bergambar Joko Tole disoroti pada bagian ketika Joko Tole sudah menjadi pemuda yang menjabat sebagai kesatria perang di Kerajaan Majapahit.

Joko Tole dikisahkan sebagai pemuda yang sederhana bertubuh tegap dan juga tampan. Ia membantu membangun pintu gerbang keraton Majapahit yang setelah itu, Joko Tole diangkat menjadi kesatria utama oleh raja. Joko Tole merupakan kesatria yang di sayang oleh Raja. Namun karena hal itu, banyak fitnah tentang Joko Tole yang akhirnya di dengar oleh Raja. Untuk menguji kesetiaan Joko Tole, akhirnya Raja menjodohkan Joko Tole dengan Putrinya, tetapi Joko Tole di dijodohkan dengan putri Raja yang buta bernama Dewi Ratnadi (Sambangsari, 2008: 143). Pernikahan keduanya di dirayakan di pusat kerajaan Majapahit. Setelah perayaan itu selesai, Joko Tole dan istrinya izin kepada Raja untuk pulang ke Sumenep. Meskipun Dewi Ratnadi buta, Joko Tole tetap menunjukkan rasa sayangnya kepada istrinya tersebut. Dalam Perjalanan, ia selalu mencarikan buah-buahan yang di sukai Putri Dewi Ratnadi. Putri tidak menyangka Joko Tole sangat akan mencintai sedemikian seperti itu. Setelah sampai di pelabuhan Gresik, Joko Tole dan Putri Dewi Ratnadi beristirahat, yang lalu mereka menaiki kapal untuk menyeberang ke ujung pulau Madura. Setelah sampai, Dewi Ratnadi ingin mandi, tetapi di sekitar tempat itu tidak ada sumur maupun sungai. Lalu, Joko Tole mengambil tongkat Dewi Ratnadi dan menancapkan nya ke tanah, setelah di cabut, keluarlah air yang sangat memancar dari tanah dan langsung membasahi wajah Dewi Ratnadi. Alangkah terkejut nya, setelah terkena air tersebut, mata Putri Dewi Ratnadi bisa melihat (Suyami, 2009).

Perjalanan selanjutnya, ketika tiba di suatu tempat, Dewi Ratnadi ingin mandi. Joko Tole melakukan hal yang sama, menancapkan tongkat ke tanah yang lalu keluar air yang deras. Setelah selesai mandi, Dewi Ratnadi terkejut karena pakaiannya dihanyutkan oleh air yang sangat deras. Tanpa pikir panjang, Joko Tole memanggil air tersebut dan air pun membelok dan mendekati Joko Tole. Perjalanan pun di lanjutkan menuju ke Timur. Setelah sampai di Sumenep. Joko Tole disambut dengan gembira oleh ayah dan bundanya serta masyarakat Sumenep. Kakak Joko Tole dari pihak ibu bernama pangeran Saccadiningrat adalah seorang Adipati atau Raja Muda. Setelah Saccadinigrat memasuki usia tua, ada sekawanan bajak laut dari Cina yang mengganggu wilayah perairan selat Madura. Joko Tole di tugaskan untuk mengamankan wilayah tersebut. Dengan bekal kuda dan cambuk api dari kakeknya, Joko Tole pun berhasil mengusir Bajak Laut tersebut, Raja Majapahit ikut gembira atas keberhasilan tersebut. Atas jasanya Joko Tole dinobatkan sebagai Adipati yang memerintah wilayah Sumenep. Menggantikan kakaknya yang sudah berusia lanjut. Di bawah kepimpinan Joko Tole, masyarakat Sumenep mengalami kemakmuran dan keadilan karena dipimpin oleh orang yang jujur dan adil (Suyami, 2009).

Cerita Joko Tole ini sangat menarik karena mengajarkan arti kesetiaan dan menolong tanpa keinginan pamrih, serta ada nilai kepahlawanan yang ditampilkan dari tokoh Joko Tole, yaitu tentang keberanian, kejujuran, rela berkorban (Maimunah, 2006: 1). Oleh karena itu, perancangan sampul buku cerita bergambar Joko Tole ini sebagai upaya untuk menarik pembaca untuk membacanya dan melestarikan cerita-cerita rakyat, terutama cerita rakyat Joko Tole. Selain itu, untuk menampilkan ciri khas bahwa cerita ini adalah cerita asli dari Madura, maka perancangan sampul depan buku cerita ini disisipkan identitas budaya Madura di dalamnya, yaitu dengan memasukan motif batik Madura dan udeng sebagai ciri khas aksesoris yang dikenakan pemuda Madura.

\section{METODE PENELITIAN}

Metode penelitian merupakan langkah yang dimiliki dan dilakukan dalam rangka mengumpulkan data serta melakukan investigasi pada data yang telah diperoleh. Metode ini 
bertujuan untuk menemukan pengetahuan baru secara ilmiah yang sebelumnya belum pernah diketahui.

Penelitian ini menggunakan metode penelitian kualitatif deskriptif. Metode ini digunakan bertujuan untuk memperoleh data untuk kepentingan pembuatan ilustrasi dan gaya visual pada sampul cerita bergambar. Dalam pembuatan karakter ini di sesuaikan dengan desain yang di sukai oleh anak-anak saat ini, namun tetap memunculkan ciri khas budaya pada objeknya.

\section{HASIL DAN PEMBAHASAN}

Buku cerita bergambar adalah buku bacaan cerita yang menampilkan teks narasi serta gambar-gambar ilustrasi (Nurgiyantoro, 2005: 152). Sejalan dengan hal itu, menurut Micthel (2003: 87) buku Cerita bergambar merupakan buku yang menyampaikan cerita disertai gambar dan keduanya saling terhubung. Dengan buku yang bergambar mampu merangsang imajinasi anak. Kegiatan membaca buku cerita bergambar dapat membantu anak lebih paham hubungan antara cerita dengan gambar yang ditampilkan.

Pada sebuah buku cerita bergambar atau komik terdapat cover atau sampul. Bagian pada sampul buku terdiri dari sampul depan, sampul belakang, punggung buku, dan lidah sampul. Artikel ini menghasilkan rancangan desain pada bagian sampul depan buku. Sampul depan merupakan tampilan depan atau muka yang terletak di bagian awal buku (Razak, 2020: 85), sehingga bagian ini merupakan bagian yang sangat penting dalam perancangan buku cerita bergambar untuk mendukung daya tarik membaca. Sampul terdiri dari tipografi, gambar, warna, dan lay-out.

Unsur-unsur pada sampul buku terdiri dari tipografi, gambar, warna, dan layout. Tipografi merupakan ilmu yang mempelajari mengenai huruf yang digunakan dalam berbagai media. Huruf memiliki potensi untuk menjelaskan bagian-bagian yang tersirat dalam sebuah komunikasi verbal yang tertuang dalam abstraksi bentuk-bentuk visual (Rustan, 2009: 18). Gambar /Ilustrasi berasal dari Bahasa latin yaitu illustrate yang artinya menerangkan atau menjelaskan. Oleh karena itu, gambar yang berfungsi untuk memberi penjelasan atau memperindah penampilan suatu tulisan disebut gambar ilustrasi.

Warna merupakan elemen grafis yang kuat. Warna dapat memberi pengaruh dalam membantu komposisi desain menjadi menarik. Terdapat dua golongan warna, yaitu warna panas dan warna dingin. Warna panas terdiri dari warna merah, jingga, dan kuning dihubungkan dengan sifat spontan, meriah, terbuka, bergerak, dan menggelisahkan. Warna panas disebut dengan extroverted colour. Warna dingin dihubungkan dengan sifat sejuk, santai, penuh pertimbangan. Warna dingin disebut introverted colour.

Tata letak atau layout merupakan salah satu unsur yang terdapat dalam mendesain, mendesain suatu media memerlukan tempat, bahan dan unsur-unsur yang dibutuhkan untuk disusun (Rustan, 2009: 30). Proses layout yaitu mengatur penempatan berbagai unsur komposisi, seperti teks atau huruf, garis, bidang, dan gambar.

\section{Analisis Khalayak}

Dalam perancangan desain sampul depan buku cerita bergambar Joko Tole ini perlu dilakukan analisis khalayak, agar pesan dalam buku ini dapat tersampaikan dengan baik sesuai dengan target yang dituju. Oleh karena itu, perlu melakukan analisis segmentasi, targeting, dan positioning. Sebagai berikut:

1. Segmentasi, perancangan ini ditujukan untuk anak-anak berusia $7-13$ tahun yang tinggal di perkotaan dan pedesaan, terutama yang tinggal di daerah pulau Madura.

2. Targeting, ditujukan untuk anak-anak Sekolah Dasar.

3. Positioning, desain sampul depan buku cerita bergambar Joko Tole ini menggunakan penggabungan gaya visual manga serta menggunakan warna yang menarik dan colorful yang dapat menarik minat baca pada anak-anak. Hal tersebut diharapkan dapat menjadi daya tarik dari sampul buku cerita bergambar Joko Tole dari Madura di mata para pembaca. 


\section{Perancangan}

Desain sampul depan buku cerita bergambar ini menggunakan teknik menggambar secara manual dengan pewarnaan dan linear digital di perangkat lunak Adobe Illustrator. Desain sampul buku cerita bergambar ini, didasari dengan isi cerita Joko Tole. Bagian cerita yang disoroti adalah ketikan Joko Toli dan Dewi Ratnadi sedang dalam perjalanan ke Sumenep, di mana Joko Tole menancapkan tongkat ke tanah lalu air keluar deras hingga menyembur ke mata Dewi Ratnadi.

Guna memunculkan ciri khas pada tokoh yang ada di dalam buku cerita bergambar ini sebagai cerita rakyat asli Madura, maka ditambahkan visual pakaian adat Madura dalam desain tokohnya. Adapun beberapa unsur pakaian adat Madura dalam desain sampul depan buku cerita bergambar Joko Tole, yaitu:

\section{Odheng}

Odheng adalah penutup kepala yang digunakan pada umumnya oleh masyarakat Madura. Bagi masyarakat Madura, odheng memiliki arti simbolis yang kompleks, baik dari ukuran motif maupun cara menggunakannya. Motif pada Odheng pun bermacam-macam yaitu ada Odheng bangsawan, tongkosan, dan juga rakyat. Bagi masyarakat Madura, bentuk dan cara memakai Odheng menunjukkan derajat kebangsawanan dari seseorang. Semakin tegak kelopak odheng, semakin tinggi pula derajat kebangsawanan. Sedangkan semakin miring kelopaknya, maka derajatnya pun semakin rendah (Prabowo, 2014: 34).

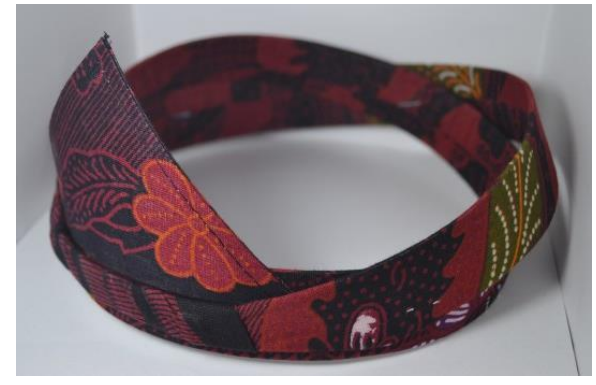

Gambar 1. Odheng

Sumber: http://artisanalbistro.com

\section{Batik}

Batik merupakan salah satu kebudayaan asal Indonesia yang sudah diakui dunia. Di Indonesia sendiri, tiap daerah memiliki Batiknya sendiri-sendiri, termasuk juga di Madura. Madura memiliki beragam ciri khas batiknya sendiri yang tergolong dalam jenis batik pesisir. Ciri Batik Madura biasanya memiliki warna yang cerah serta motif yang dinamis. Namun selain itu terdapat juga batik Madura yang mirip dengan batik-batik dari daerah Yogyakarta dan Surakarta. Jenis batik Madura yang digunakan dalam desain sampul ini adalah petengteng klasik motif kupu dan batik bangkalan motif tumbuhan.

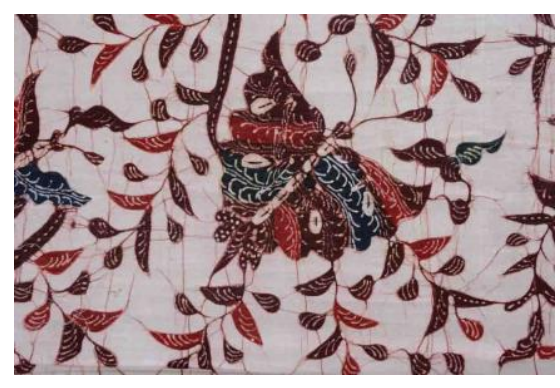

Gambar 2. Batik Madura Jenis Petengteng Klasik Sumber: https://bergaya.id/batik-madura/ 


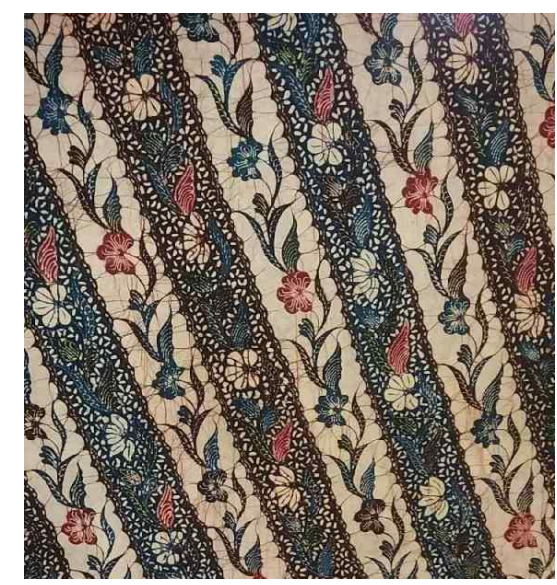

Gambar 3. Batik Madura Jenis Bangkalan

Sumber: http://dharmawanitapersatuan.com

\section{Tipografi}

Tipografi diperlukan agar para pembaca dapat memahami bahwa desain sampul ini ditujukan untuk anak-anak, maka penggunaan font yang digunakan adalah font Bakso Sapi.

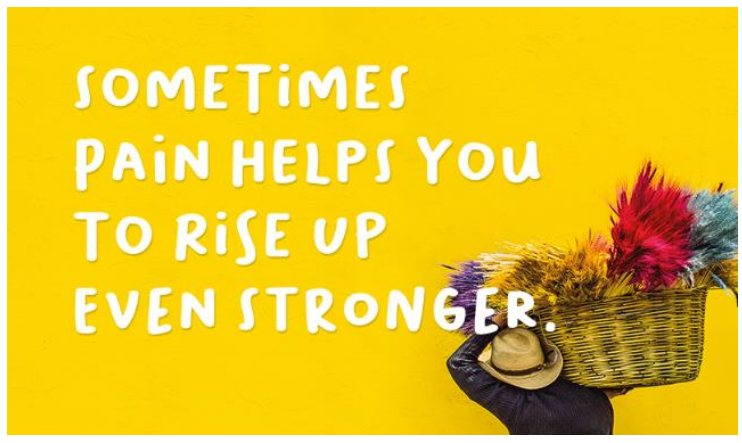

Gambar 4. Font Bakso Sapi

Sumber: https://www.dafont.com/

Jenis huruf ini termasuk pada kategori Sans Serif sehingga berkesan ceria dan lucu tetapi masih mudah untuk dibaca, dan dapat dapat diterima oleh anak-anak. Digunakan pada judul utama buku.

\section{Warna}

Warna yang digunakan dalam desain sampul depan buku cerita Joko Tole ini di dominasi dengan warna terang dan juga benuansa gelap. Hal ini dikarenakan latar pada sampul buku cerita bergambar ini, menggunakan latar pada saat Joko Tole sedang melakukan perjalanan ke Sumenep dan melewati hutan, tetapi juga warna pakaian Dewi Ratnadi menggunakan warna terang karena dia adalah seorang Ratu. 


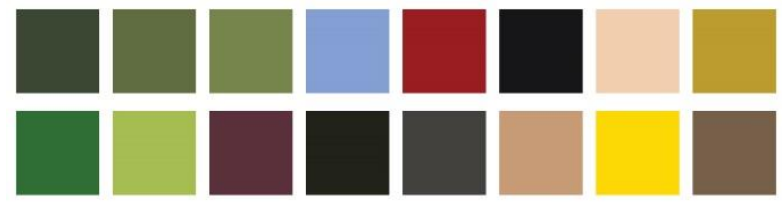

Gambar 5. Aplikasi Warna Pada Sampul Depan Buku Cerita Bergambar Joko Tole Sumber: Dokumentasi Pribadi

\section{Ilustrasi atau Gambar}

Dalam mendesain sampul depan buku cerita bergambar Joko Tole ini, dibuat ilustrasi saat Dewi Ratnadi ingin mandi tetap tidak ada sungai atau sumber mata air di sekitar, sehingga Joko Tole mengambil tongkat lalu menancapkan ke tanah sehingga keluar air yang sangat deras sehingga Dewi Ratnadi terkena air tersebut. Gaya gambar pada desain ini adalah gaya gambar manga, karena saat ini anak-anak banyak tertarik dengan gambar manga ataupun juga anime dari Jepang. Berikut langkah-langkah peneliti membuat sampul depan buku cerita bergambar Joko Tole:

1. Sketsa kasar

Langkah pertama yang dilakukan adalah membuat ilustrasi berupa sketsa kasar secara manual dengan menggunakan pensil.

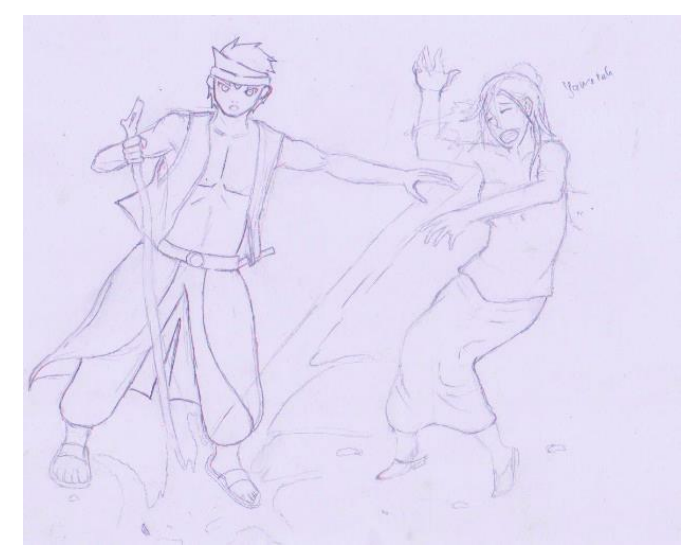

Gambar 6: Sketsa kasar Sampul depan buku Cerita Bergambar Joko Tole Sumber: dokumentasi pribadi

Gambar sampul depan bergambar Joko Tole bersama istrinya. Joko Tole sedang menancapkan tongkat kepunyaan Istrinya, lalu saat dicabut keluar Air yang lalu mengenai Istri Joko Tole yaitu Dewi Ratnadi. Sampul ini menggambarkan sedikit dari cerita Joko Tole.

2. Sketsa Halus

Berdasarkan sketsa kasar di atas, proses selanjutnya adalah melakukan tracing karakter secara digital. Selain tracing karakter, di proses ini juga menambahkan background, judul dan juga pewarnaan. Proses ini dilakukan menggunakan software Adobe Illustrator. Pada background, ditampilkan gambaran hutan, saat Joko Tole beserta Dewi Ratnadi melakukan perjalanan ke Sumenep. 


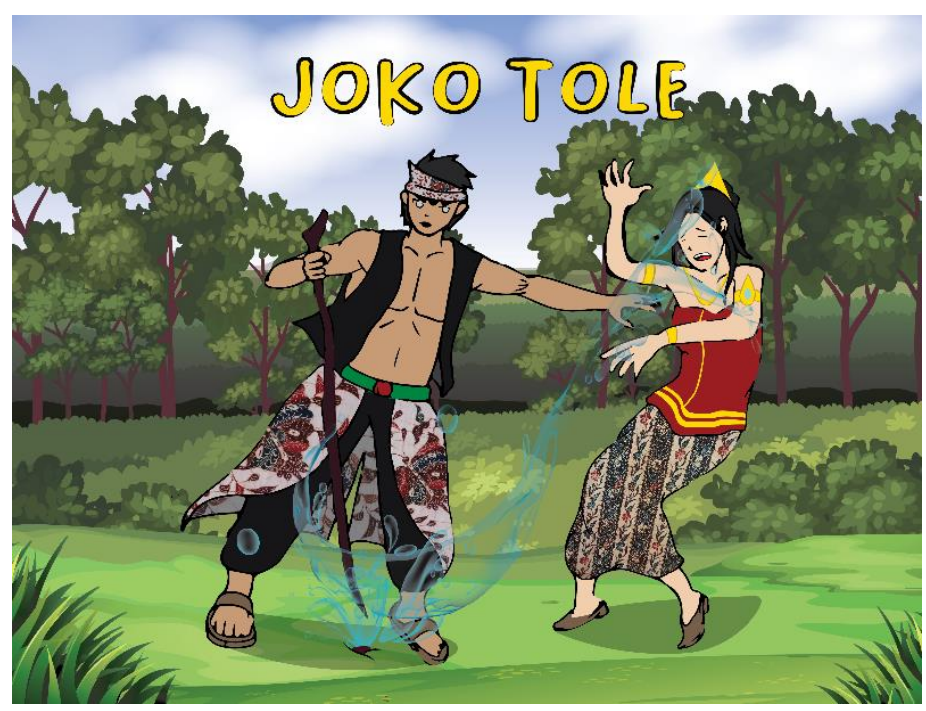

Gambar 7. Desain Sampul buku cerita bergambar Joko Tole Sumber: dokumentasi pribadi

Desain sampul depan buku cerita bergambar Joko Tole yang telah dibuat ini diharapkan dapat disukai dan tepat pada analisis khalayaknya. Sampul depan buku ini merupakan proses awal dari rangkaian perancangan buku cerita bergambar Joko Tole secara utuh. Warna yang ditampilkan pada desain sampul depan ini adalah warna-warna cerah yang disukai oleh anakanak. Diharapkan dengan adanya sampul depan buku ini mampu memvisualkan tokoh Joko Tole dan Dewi Ratnadi sebagai salah satu bagian dari cerita rakyat Madura, sehingga karakter tokohnya memiliki identitas yang berbeda dengan karakter tokoh pada cerita rakyat lainnya.

\section{SIMPULAN}

Buku Cerita Bergambar Joko Tole ini menceritakan tentang kisah seorang pemuda bernama Joko Tole yang mengajarkan tentang sifat kebaikan, ikhlas, rela berkorban dan juga menolong tanpa pamrih. Cerita ini juga mengenalkan kepada anak-anak mengenai kebudayaan Madura. Tujuan dari penelitian ini adalah untuk merancang sampul buku cerita bergambar yang ditargetkan kepada pembaca anak-anak maupun remaja terutama yang tinggal di daerah Madura, serta memunculkan identitas budaya Madura pada desain yang ditampilkan. Sampul buku adalah hal pertama kali yang dilihat oleh para pembaca, dan menjadi penentu apakah para pembaca akan tertarik atau tidak. Oleh Karena itu, perancangan sampul buku cerita bergambar Joko Tole merupakan salah satu upaya untuk menarik minat anak-anak untuk membaca buku cerita rakyat.

\section{DAFTAR PUSTAKA}

Kusrianto, A. (2010). Pengantar tipografi. Jakarta: PT Elex Media Kumputindo.

Maimunah, S. (2006). Nilai kepahlawanan dalam cerita rakyat Madura Joko Tole. Skripsi Jurusan Pendidikan Bahasa Indonesia, fakultas Keguruan dan Ilmu Pendidikan Universitas Muhammadiyah Malang.

Mitchell, D. (2003). Children's literature: Animation to the world. USA: Allyn \& Bacon.

Nurgiyantoro, B. (2005). Satra anak pengantar pemahaman dunia anak. Yogyakarta: Gadjah Mada University Press. 
Prabowo, A. B. D. (2014). TA: Pembuatan Video Pembelajaran Pakaian Adat Madura Dengan Penggabungan 3D dan Live Shot (Doctoral dissertation, STIKOM Surabaya).

Razak, A. H., widya Wardani, W. G., \& Saptodewo, F. (2020). Perancangan sampul buku cerita bergambar asal usul Kota Tanjungpinang. Visual Heritage: Jurnal Kreasi Seni dan Budaya, 2(2), 83-88.

Rustan, S. (2009). Layout: Dasar dan penerapannya. Jakarta: PT Gramedia Pustaka Utama.

Sambangsari, S. (2008). Kumpulan cerita rakyat Nusantara. Jakarta: Wahyu Media.

Suyami. (2009). Cerita Jaka Tole dalam kehidupan masyarakat Sumenep Madura. Yogyakarta: Departemen Pendidikan dan Kebudayaan. 